obtained now, the laboratory will be opened next summer. The following is a list of the lecturers and their subjects : Jan. I8, Prof. W. H. Niles of the Massachusetts Institute of Technology, 'Mountain Sculpture;' Jan. 25, Maj. J. W. Powell, director of the United States Geological Survey, 'Savagery, Barbarism, and Civilization ;' Feb. I, Prof. H. N. Martin of the Johns Hopkins University, 'A Hen's Egg;' Feb. 8, Prof. George L. Goodale of Harvard College, 'Seeds;' Feb. 15, Prof. F. W. Putnam, director of the Peabody Museum of American Archæology and Ethnology, at Cambridge, 'The Serpent Mound and the Ancient People of the Ohio Valley;' Feb. 22, Prof. Alpheus Hyatt, curator of the Boston Society of Natural History, 'A practical Example of the Evidence for Evolution;' Feb. 29, Dr. Henry P. Bowditch, dean of the Harvard Medical School (subject to be announced); March 7, Prof. Edward S. Morse, director of the Peabody Academy of Science, Salem, ' Reptilian Affinities of Mammals.'

LETTERS TO THE EDITOR.

"* Correspondents are requested to be as brief as possible. The zuriter's name is in all cases required as proof of good faith.

Twenty copies of the number containing his communication will be furnished free to any correspondent on request.

The editor will be glad to publish any queries consonant with the character of the journal.

\section{The Trinity Formation of Arkansas, Indian Territory, and Texas.}

DURING the past field-season the writer has had an opportunity to study the small mesozoic area in the south-west corner of the State of Arkansas and south-eastern Indian Territory, which is the north-eastern termination of the great area so well developed to the southward in Texas. By courtesy of Dr. John C. Branner, State geologist, I am permitted to publish the following note in advance of the more detailed official report which will soon be published by him.

In previous papers (American Naturalist, Feb. 1887; American Tournal of Science, April and October, I887) I have shown that the mesozoic strata of the Texas region, instead of belonging to the uppermost cretaceous as had been previously supposed, really embraced a large series of lower cretaceous and perhaps Jurassic beds. To the last-named period I intimated that the strata in Parker County, Tex., provisionally termed in my section the 'Dinosaur Sands,' would probably be found to be related. The studies of the past season in Arkansas have shown that these strata exhibit great uniformity of deposition along the paleozoic and mesozoic parting from south of the Brazos River in Texas, to the Little Missouri River near Antoine, Pike County, Ark., a distance of over three hundred miles, and that they rest directly upon the highly disturbed carboniferous rocks. In Texas the areal extent of this formation coincides with the eastern half of the Upper Cross Timbers, and in Arkansas it extends from the point above mentioned westward to beyond Ultima Thule. Its width, except for a few miles on each side of Red River, never exceeds a few miles. The formation consists of alternations of fine, closely packed white sands and red and blue gypsiferous marls, with occasional alternations of thin but extensive, fissile, arenaceous, and crystalline limestones, highly fossiliferous, often wave-marked, and seldom more than ten inches in thickness. Extensive strata of pure saccharoidal gypsum also occur in places, and the formation is the source of the salines and salt licks throughout its extent, and probably also of the 'brackishness, of the rivers which intersect it.

This formation is clearly distinguished from the overlying cretaceous (which deposits are later and later as we proceed eastward along the contact) and the underlying carboniferous. West of Weatherford the basal Comanche series may be seen resting directly upon it, while, at the point of its disappearance under the newer strata in Arkansas, it is directly covered by the uppermost cretaceous of Hilgard's Mississippi section.

The fauna of this formation is littoral and of great uniformity throughout its extent, and, upon hasty observation, conveys an impression that it is later than it really is. It consists of characteristic molluscan species which are hardly distinguishable from certain characteristic European forms specially indicative of the Upper Jurassic and Wealdan. I hope to give more detail concerning these fossils in a special paper hereafter. In Texas I found what are at present supposed to be dinosaurian remains ; and occasional vegetal remains are met with.

To the continuous formation the name of 'Trinity' is applied, from the rivers of that name which arise in it. This includes the strata which I termed 'Dinosaur Sands' in my Texas section.

The discovery of these trans-Mississippi beds of Jurassic affinities is of importance, in that it indicates a close relation and possible continuity between the pre-cretaceous mesozoics of Colorado and the Texas Pan-handle, and the Tuscaloosa and Potomac beds of the cis-Mississippi region.

U. S. Geol. Surv., Washington, D.C., Jan. 6.

\section{Children's Development.}

RECENTLY I became interested in the vocabulary of my boy, thirty months old, and for one day noted all words used by him, except proper names. No effort was made to exhaust the child's stock of words by questioning. He used three hundred and fiftytwo words, of which fifty-four per cent were nouns, eighteen per cent verbs, and eleven adjectives. It is probable that the child's entire vocabulary of dictionary words includes four hundred or more.

Washington, D.C., Jan. 4.

G.

\section{Is there a Venomous Lizard (Heloderma)?}

THIS animal has been an object of considerable interest to naturalists because of the question whether or not it presents the anomaly of a venomous lizard. Just before leaving the United States, last September, I had under my care about twenty so-called 'venomous lizards' of various ages and sizes; and, as I believe the biography of this animal has been but slightly touched on, a few observations in regard to them may not be out of place.

They varied in length from 19 to 49.5 centimetres. The larger ones, say above 43 centimetres, were all females. Their colors ranged from almost a brick-red to pale pinkish white, with markings from black to vandyke brown, which showed no regularity in details, appearing as if each lizard had been the subject of some Chinese artist who ajmed only at the general effect. They all came to my father's establishment, in Rochester, by express; and the shakingup and lack of freedom that they had undergone served to make them very irritable. When first liberated from their confining boxes, their first desire was to get hold of the nearest person, and, although usually very sluggish, they would then move with surprising agility, turning end for end, and making short dashes hither and thither with great swiftness. When one succeeded in fastening its teeth in my clothes, it held on with the tenacity of a bull-dog, occasionally giving a vicious shake to its head, as if trying to tear away a piece of the cloth. Nor was this pugnacity confined alone to the time of their arrival, but continued in lesser degrees during the entire time that I had them under observation. Once I saw a pitched battle between two. One had its teeth firmly fixed in the throat of the other, who, in turn, had a leg of the first in its jaws. Together they rolled and twisted over the floor, neither relaxing its hold for a period of fifteen minutes. Blood was drawn on both sides, yet neither afterwards appeared the worse for the conflict. I then tried two of them on a hen, to ascertain if they would prove poisonous to her. Having first shaved the thigh of the hen, so that the feathers might not interfere wth the entrance of any poison, I induced one of the lizards to take hold. This it readily did, and retained its grip for five minutes, occasionally shaking its head in a savage manner. During the operation the hen appeared quite impassive, and, although not tied, made no attempts to escape, evidently charmed by the lizard. A little blood was drawn, showing that the flesh had been thoroughly pierced. For perhaps a half-hour afterwards the hen appeared a trifle stupid, but soon regained its normal condition, and gave no signs at all of poisoning. Two days later I repeated the experiment with another lizard, with a similar lack of results. I then caused one of them to bite the edge of a saucer, and, with a hypodermic syringe, injected the fluid obtained in the breast of a pigeon. No effect. Then, exciting one so that it viciously bit a small piece of wood, I drew a considerable quantity of fluid direct from its mouth, which, injected into the pigeon's breast, produced no results. 
However, birds and lizards are bad subjects for experimenting upon with supposed poisons, and do not conclusively prove that they might not be poisonous, or perhaps even fatal, to man. But being very busy at the time, I had no opportunity to carry my experiments further.

The forked tongue continually playing in and out of the mouth like a serpent's, the snake-like hiss, and the bright colors, together with their aggressive disposition, are well calculated to excite the suspicions of the Arizona Indians, who are reputed to greatly fear and thoroughly believe in the extreme venomousness of this reptile.

When intent on going anywhere in particular, their gait changes from a dragging of the body along the ground to that which an alligator assumes under similar circumstances; i.e., the body is carried high on the legs, clear from the ground, and the tail carried rigid and in line with the body.

They showed a peculiar fondness for water. When placed in a large tank with sloping bottom, in one end of which was water, all would spend most of their time lying where it was about an inch deep. This appears strange when recalling the arid character of the plains that they inhabit.

Their rations consisted of raw hen's-eggs, one of which made a full meal for a good-sized individual, which would not appear to care to dine more than once in about four days. These were given whole to the larger ones, which, having gotten the egg fairly in their jaws, experienced no difficulty in breaking the shell. Their mode of eating is by running the tongue into the mass of the egg, drawing it into the mouth, repeating this in a very deliberate manner, and spending from twenty minutes to a half-hour on an egg.

Their ability to climb is considerable; quite out of keeping with their heavy, unwieldy appearance. A tolerably smooth stick, an inch in diameter, standing at an angle of about sixty degrees, is quite easily ascended.

Several of them laid eggs during August and September. These were 53 millimetres long by 26 millimetres in transverse diameter, were perfect ellipsoids, having a finely granulated, soft, tough, translucent skin or shell.

Tambaya, D.F., Mex., Dec. 25.

\section{Sections of Fossils.}

IN Science for Nov. I8, Prof. Joseph F. James, in speaking of the production of sections of Bryozoa for microscopic examination, says, "I can quote no higher authority than Mr. Archibald Geikie (Text-Book of Geology, pp. 85-88, where elaborate directions are given for making rock sections; Professor Prestwich also considers it ' an expensive and tedious process,' Geology, i. p. 43) as to the tediousness of the process." The pertinence of these references immediately vanishes if a person take but the pains to look them up. In both it will be found that the authors have been referring to the making of slides of Plutonic and metamorphic rocks. Of course, any one knows that a limestone in which Bryozoa are usually embedded cuts far more readily than crystalline rocks. Now, with a little practice, a man can soon cut from six to ten slides of crystalline rocks in a day; and he can cut six times as many slides of calcareous Bryozoa in the same time, as I have often seen done by college students, not by lapidaries. An average of from forty to sixty slides a day certainly cannot be complained of. Of course, no one will deny that the use of the microscope in fine petrographical studies of crystalline rocks has become imperative. We are here referring to Bryozoa.

Feeling convinced, from my own study of the writings of these authors, that they had never expressed an opinion of this subject, least of all with special reference to the Bryozoa, I sought for further information. Under date of Dec. Io, Prof. Joseph Prestwich writes me, "The question you ask about the Bryozoa is quite beyond my knowledge. I have never studied the Bryozoa. In fact, there are very few persons in England who have studied them. We lost our great authority in my old friend Mr. George Busk." In a letter dated Dec. 8, Prof. Archibald Geikie writes, "The question you propose to me in your letter is really one to which I do not feel myself competent to give an answer. I haver never given special study to the Bryozoa, and I have nowhere ventured to publish an expression of opinion."

The sentence quoted from Professor James's article concludes with the following words: "nor a better one than Dr. Nicholson as to the uncertainty of the results." In my article of Nov. 4, I mentioned Prof. H. A. Nicholson as one of the leading men who first took a decided stand in favor of the prominent use of internal characters as a means of classification. Now, it would not be fair to construe the above sentence as meaning that Professor Nicholson's writings are themselves a manifest example of the viciousness of the methods pursued by the new school. It must mean, therefore, that Professor Nicholson does not believe in the use of these microscopic sections. Since we interpret the spirit of Professor Nicholson's 'Genus Monticulipora' (I88I) and 'Tabulate Corals' (I879) so differently, it will certainly be fair to quote his later writings, since they at the same time must contain his more mature views. Thus in the Annals and Magazine of Natural History, February, I 884, he writes, "The earlier observers of these fossils, as, for example, Mr. Lonsdale, necessarily founded their names upon macroscopic characters principally, the method of investigation by means of thin sections being of recent origin ; and they also gave, as a rule, extremely brief descriptions. Hence it is exceedingly difficult, in many cases, among the monticuliporoids, to be certain as to the precise forms to which the older names should be attached." Then he proceeds to an investigation of both external and internal characteristics, accompanying the same with figures, of which those illustrating internal features alone are of value. In the number for December, I885, he and Foord discuss the genus Fistulipora on the basis of the new light cast upon it by an investigation of the internal structure. Again in May, I886, they make use of this method when they say, "Having recently had the opportunity of making a microscopical examination of a very extensive series of these forms, we have satisfied ourselves that they cannot be referred to the genus Chatetes, Fisher." And they propose the new genus Rhaphidopora. The plates I5, 16, and I7, accompanying this article, do not leave any cloubt as to the position taken by these authors. The same is true of an article published by Nicholson and Etheridge in the same journal (March, I886), where indeed they go so far as to separate Stenopora australis from S. ovata, with which "the specimens in question agreed entirely in external form and in macroscopic characters," solely on the basis of distinct internal features.

I cannot do better to express the opinions which actuate the new school of students than to quote from a letter from Prof. Archibald Geikie: "The common-sense view of such questions seems to me to be this. In dealing with fossils we are precluded in a vast number of cases from appealing to the evidence of internal structure, for it has not been preserved. Hence, if an organism can be satisfactorily determined from external characters, that is the most desirable means of identification, for it is the most generally applicable. If external characters are proved to be insufficient, and even misleading, we must fall back on internal structure when we can get it." Now, the new school believe that external characters often are misleading, where internal characters may more safely be followed. Since any Bryozoa, to be determined even according to the old method, must have the minute external structure well shown, and since in these cases the minute internal structure is also usually well preserved, we believe that the new method is eminently practicable. Nobody denies that external characters may be of great additional assistance.

Cambridge, Mass., Dec. 29.

\section{Weather-Predicting.}

IT has become a well-worn adage that half of the disputes would be avoided if the disputants had a thorough mutual understanding of the terms used by each. In weather predictions and verifications a clear understanding of the meaning of the terms used certainly seems very necessary. If a weather-predictor concludes that a satisfactory definition of a fair day is one on which less than .or of an inch of rain falls, and a foul day is one on which more than or of an inch falls, and makes predictions accordingly, his predictions, when verified by this rule, will give a certain success in proportion to his skill. If, now, some one should object to cloudy days without rain being called fair, and record all cloudy days for which fair weather had been predicted as failures, he would give the predictions a much lower percentage of success 